\title{
التوقيف للنظر للحدث على ضوء قانون 15 - 12 المتعلق بحماية الطفل
}

\author{
ليطوش دليلة \\ جامعة الإخوة منتوري قسنطينة
}

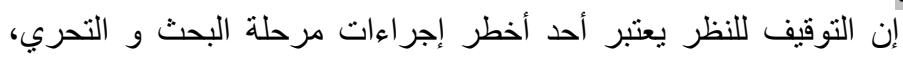

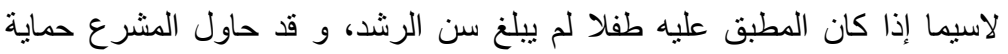

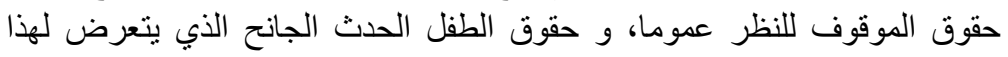
الإجراء خصوصا حينما استحدث القانون رقم 15 - 12 المتعلق بحماية الطفل،

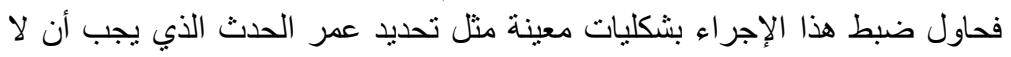

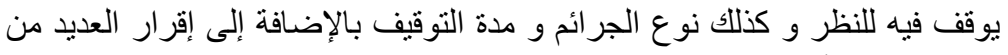

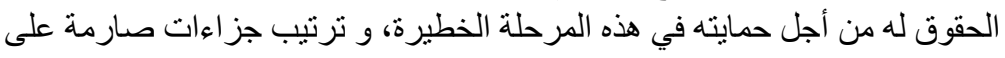

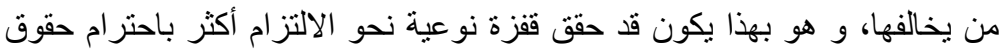
الطفل و خصوصيته و حريته.

\begin{abstract}
:
The custody is one of the gravest procedures of research and investigation, especially if it is applied to a child did not reach (effect) adult's age, the legislator tried to protect the rights of the arrested generally and the children rights subjected to this procedure in particular.
\end{abstract}

During the introduction of the law $\mathrm{n} 15-12$ relative to the protection of the child, it tried to adapt to this procedure certain formalities such as the determination of the event for which the shouldn't arrested, also the nature of breaches and the duration of arrest.

In addition to adopting other rights to protect him in this dangerous period of investigation and order a strict sanctions on people who do not respect them. 
و تعتبر مرحلة التحريات الأولية أحد أهم المراحل التي جند لها المشرع ترسانة من النصوص القانونية لغاية واحدة هي الكثف عن خيوط الجريمة التي تزايدت، و في خضم كل هذا كان

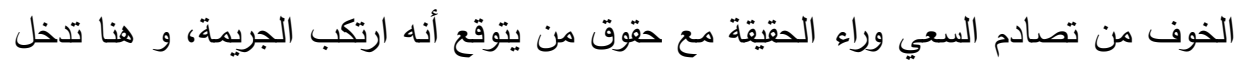

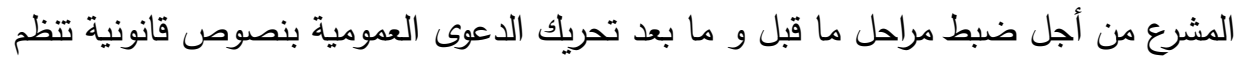

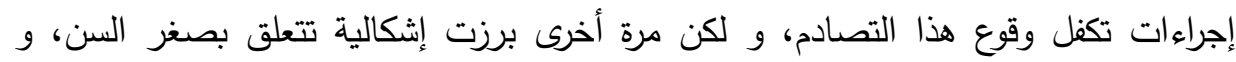

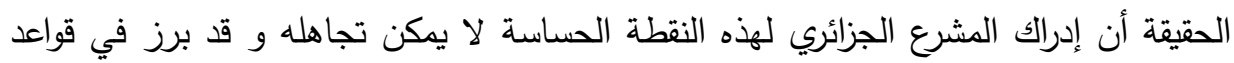

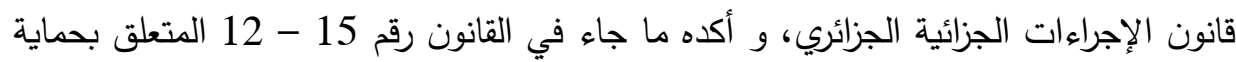

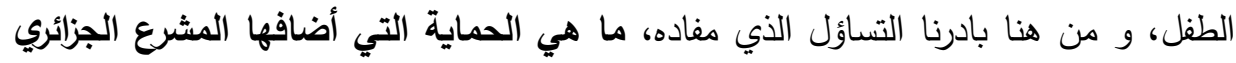

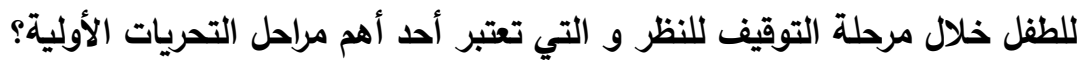
و من خلال منهج تحليلي حاولنا الإجابة عن هذا التساؤل في إطار مبحثين، تتاول (الأول) نطاق تطبيق التوقيف للنظر على الحدث الجانح، و تتاول (الثاني) حقوق الطفل الجانح الموقوف للنظر و آليات احترامها. المبحث الأول: نطاق تطبيق التوقيف للنظر على الحدث الجانح لقد اهتم الشرع الجزائري بالقواعد الثكلية الواجب إتباعها منذ وقوع الجريمة و إلى غاية

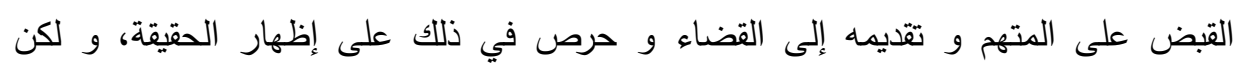
لضرورات مرحلة التحري أقر التوقيف للنظر و أكد على العمل به في القانون رقم 15 - 12

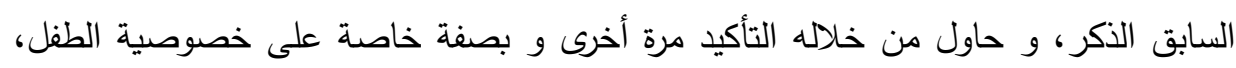

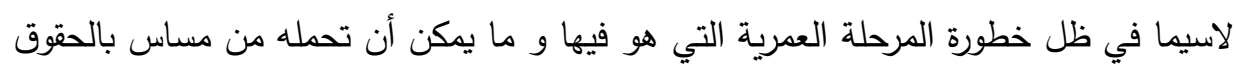
و الحريات.

المطلب الأول: الإطار المفاهيمي لتوقيف الحدث للنظر

من أهم المبادئ الدستورية التي وردت أن الحريات الأساسية و حقوق الإنسان و المواطن

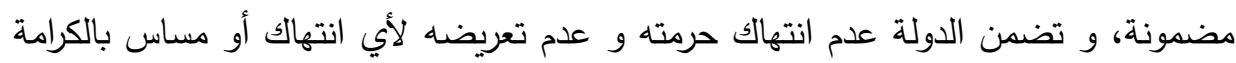


و غير ذلك...(1) و من خلال هذا نجد أن المشرع الجزائري أقر مبادئ دستورية تحمي كل الأفراد و هذا من أجل الابتعاد عما يسمى بالدولة البوليسية التي لا مكان لكرامة الفرد فيها.

\section{الفرع الأول: مفهوم التوقيف للنظر}

للتوقيف للنظر معان عديدة، فنجد أنه من الناحية القانونية اختلف في تسمية هذا الإجراء في التشريع الجزائري عنه في التشريعات المقارنة، فالمشرع الجزائري سماه "الحجز تحت المراقبة" ليغيره فيما بعد إلى "التوقيف للنظر" بعد تعديل قانون الإجراءات الجزائية بالقانون رقم 90-

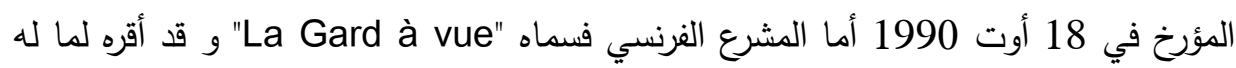
من أهمية و ملائمة للواقع و تخفيفه عن الجهاز القضائي(2)، و بالنسبة للمشرع المغربي فسماه

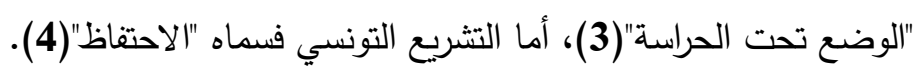

و الحقيقة أن المشرع الجزائري في قانون الإجراءات الجزائية لم يعرف التوقيف للنظر، و

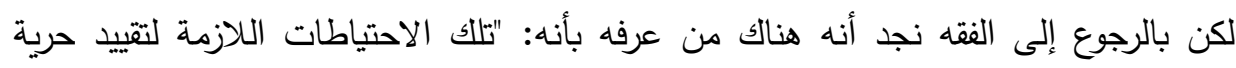

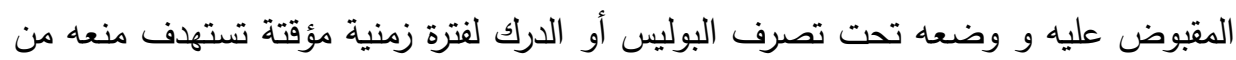

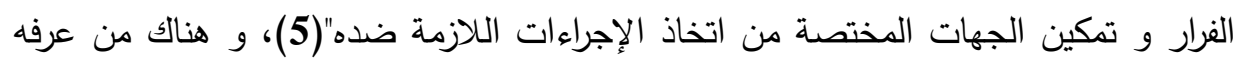
بأنه: "إجراء بوليسي يتم بواسطة ضباط الشرطة القضائية لمدة زمنية معينة فيوضع في مراكز

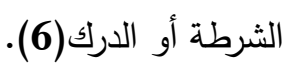

و بهذا فالتوقيف للنظر إجراء قائم بذاته يختلف عن الاستيقاف و القبض، و قد أثار ردود

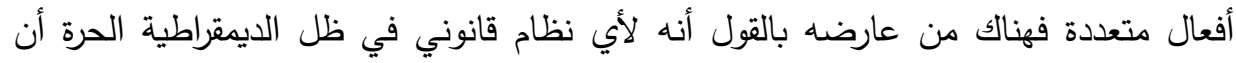
يعترف بحالتين فقط حالة الشخص حرا و حالته محبوسا، أما التوقيف للنظر فهي حالة تكون

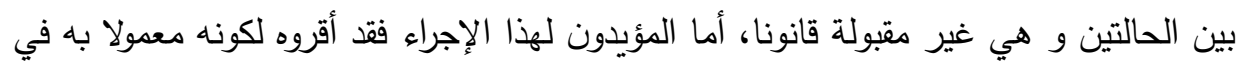

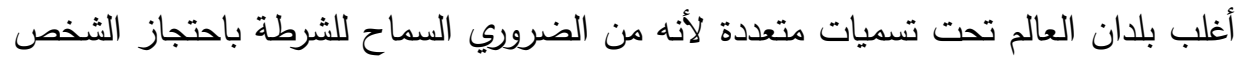

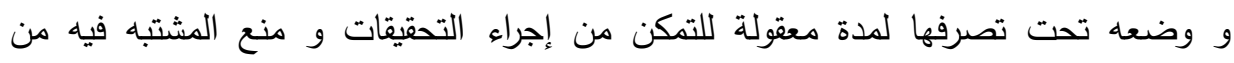

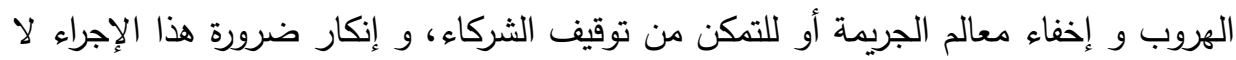

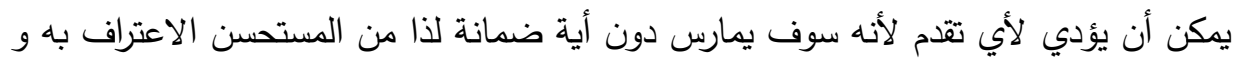
عدم تجاهل وجوده. 


\section{الفرع الثاني: مفهوم الحدث الجانح}

إن الحدث هو ذلك الثخص الذي لم يبلغ بعد سن الرشد المقرر قانونا أي الثامنة عشر سنة

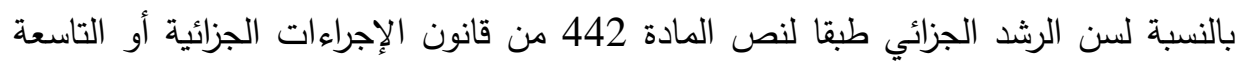
عشر سنة بالنسبة لسن الرشد المدني، طبقا لأحكام المادة 40 من القانون المدني الجزائري. و قد ورد في المادة 2 من القانون رقم 15 - 12 المتعلق بحماية الطفل (7) أنه: "يقصد في مفهوم هذا القانون كما يأتي: "الطفل" كل شخص لم يبلغ الثامنة عشر (18) سنة كاملة، يفيد مصطلح "الحدث" نفس المعنى..."، أما الحدث الجانح فهو كل شخص لم يكمل سن الرشد الجزائي و ارتكب فعلا

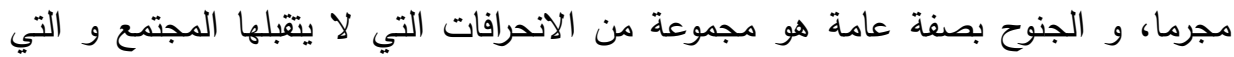

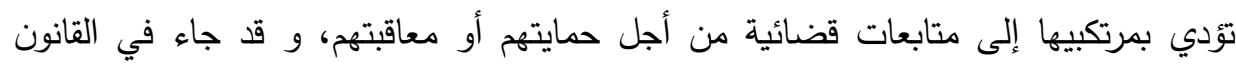

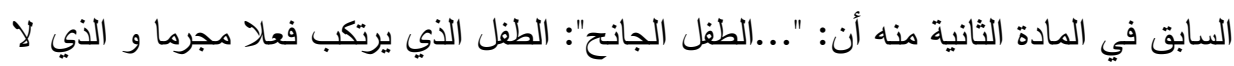
يقل عمره عن عشر (10) سنوات.

و تكون العبرة في تحديد سنه بيوم ارتكاب الجريمة ..."، و قد ذهبت معظم التشريعات المقارنة

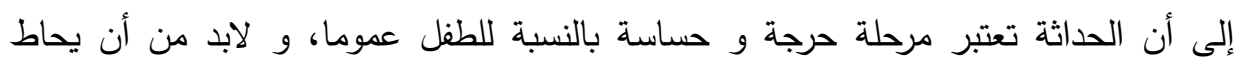
بالاهتمام و خصوصا حين الاشتباه فيه و قبل تحريك الدعوى العمومية ضده (8). و الملاحظ أنه إلى غاية صدور القانون رقم 15 - 12 السابق ذكره لم تتغير نظرة المشرع الجزائري إلى الحدث فقط نجد أنه أضاف خطوة أخرى تتمثل في تثمين سعيه بإفراد القانون

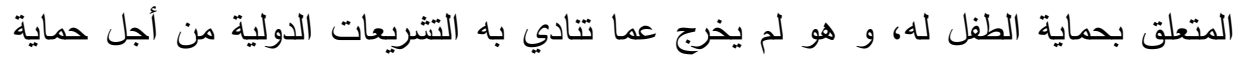

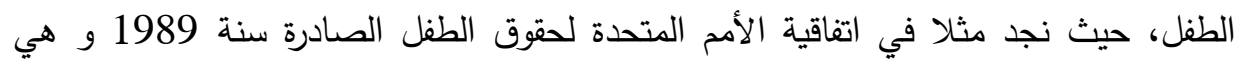
الوحيدة التي تتصدى مباشرة لمسألة تعريف الطفل بصورة صريحة، و يعلل بعض الفقهاء

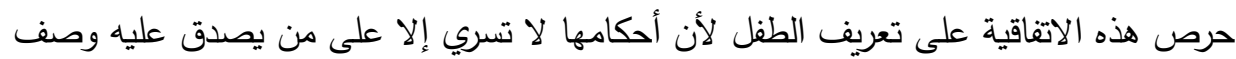

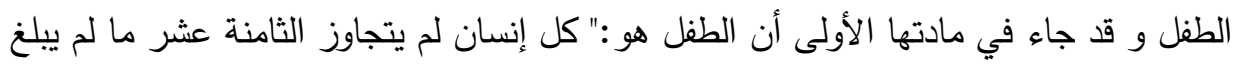
سن الرشد قبل ذلك بموجب القانون المطبق عليه"(9). 


\section{المطلب الثاني: نطاق تطبيق التوقيف للنظر على الحدث}

إن التوقيف للنظر الموقع على الحدث تتجاذب شروطه قانونين القانون رقم 15 - 12

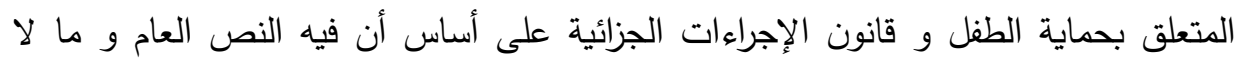
يوجد في القانون الأول يرجع إلى هذا الأخير لاسيما بالنسبة للنصوص التي تتعلق بالتوقيف للنظر الموقع على الثخص البالغ.

الفرع الأول: شروط توقيف الحدث للنظر

إن أحد أهم الثروط التي لابد من توفرها هي وجود مرحلة من المراحل التي أقر فيها الششرع

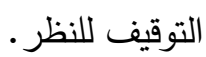

حيث لجأ المشرع الجزائري عموما للتوقيف للنظر عند التلبس بالجرائم حسب نص المادة 41

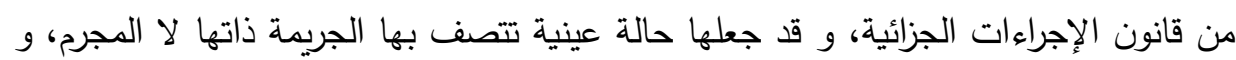

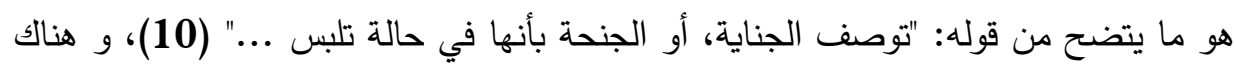

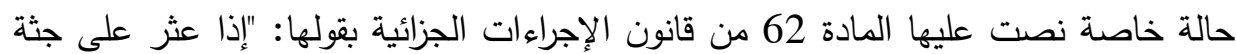

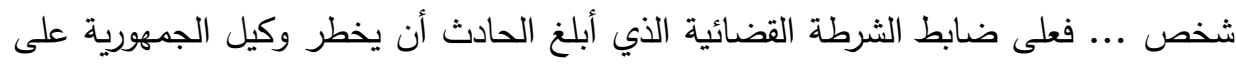

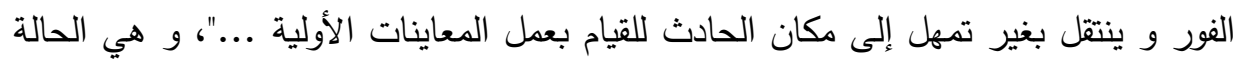

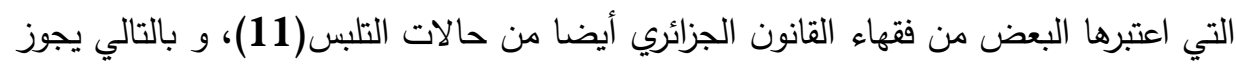

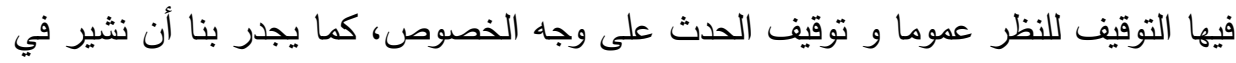

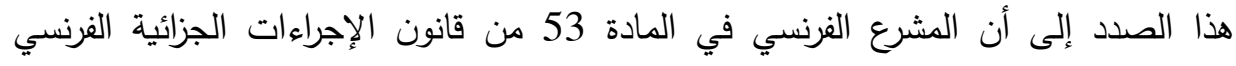
المعدلة بالقانون 204- 2004، المؤرخ في 2004/03/10، عدة فرضيات تطبق عليها القواعد الإجرائية نفسها و من بينها التوقيف للنظر و هي: الجريمة المتلبس بها بالمعنى الحصري، و الجريمة المعتبرة متلبس بها، و الجريمة المتمثلة بالجريمة المتلبس بها...(12). كما أنه يكون حسب القواعد العامة التوقيف للنظر أثناء التحريات الأولية حيث يقوم ضابط

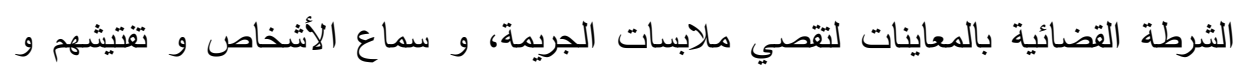

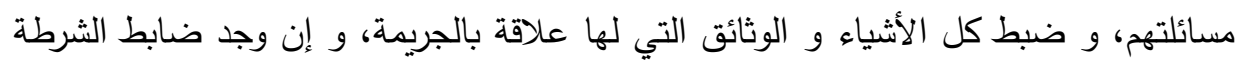


ضرورة لحجز حرية مشتبه فيه من أجل كثف معالم الجريمة لجأ إلى التوقيف للنظر في هذه

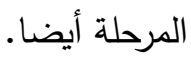

و أحيانا يجوز التوقيف للنظر بمناسبة تتفيذ إنابة قضائية و هذا طبقا لنص المادة 141 من قانون الإجراءات الجزائية (13)، و هذا لكون المشرع في نص المادة 13 من نفس القانون فتح منفذا استثائيا للضبطية القضائية يعودون من خلاله للدعوى العمومية و ذلك بتتفيذهم لها أمرهم به المشرع في نص هذه المادة حين قال: "إذا ما افتتح التحقيق فإن على لفئ الضبط القضائي تتفيذ تفويضات جهات التحقيق و تلبية طلباتها".

أما بالنسبة للقانون رقم 15-12 المتعلق بحماية الطفل فلم يشر إلى المرحلة التي يكون فيها

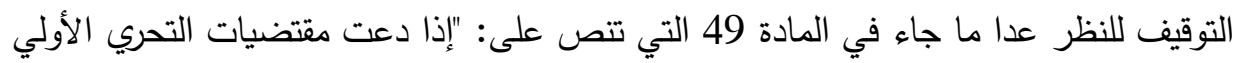
ضابط الثرطة القضائية أن يوقف للنظر الطفل الذي يبلغ ثلاث عشرة..."، و بهذا نجد أن هذا النص الخاص جاء على وجه العموم و ليس فيه تعارض مع الحالات العامة التي سبق ذكرها

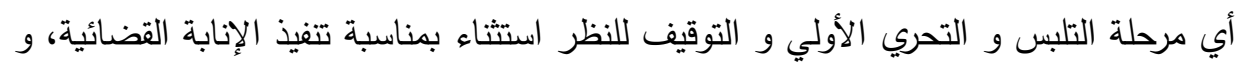
بهذا يمكن القول أنه يخضع الحدث الجانح في هذه الحالة إلى نص المادة 49 من القانون رقم 15-12 المتعلق بحماية الطفل و للحالات العامة الموجودة في قانون الإجراءات الجزائية لأنه لا يوجد ما يمنع ذلك.

و من أهم الشروط أيضا ما جاء في نص المادة 48 من القانون رقم 15- 12 السابق ذكره

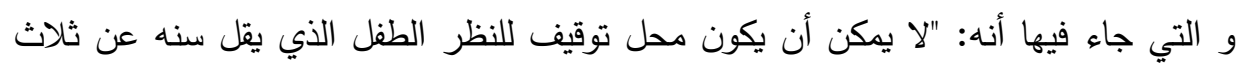

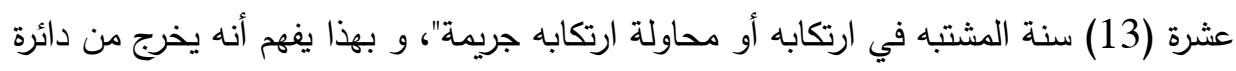

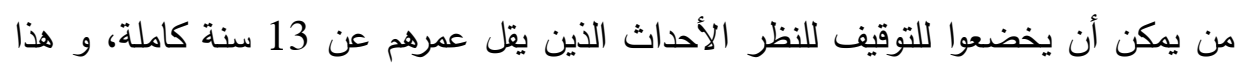

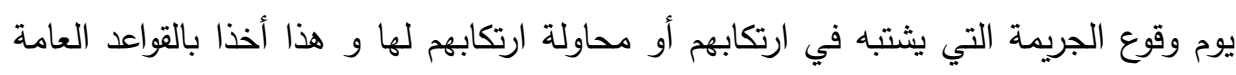

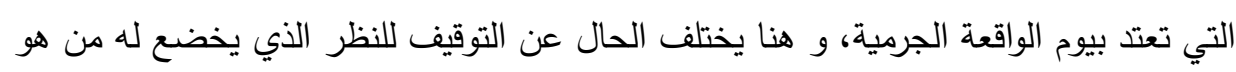
بالغ سن الرشد، كما يعتبر أيضا من شروط التوقيف للنظر الذي يخضع لهاء لها الحدث الجانح

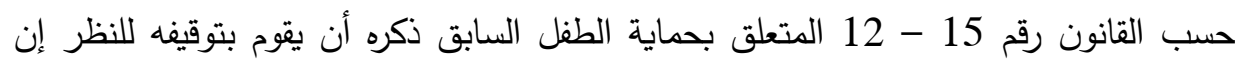

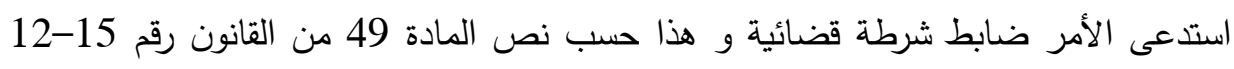
المتعلق بحماية الطفل السابق ذكره و التي جاء فيها: "إذا دعت مقتضيات التحري التهاتئ الأولي 
ضابط الشرطة القضائية أن يوقف للنظر الطفل الذي يبلغ سنه ثلاث عشرة (13) سنة..." و بهذا لا يمكن أن يوقف هذا الأخير عون من أعوان الشرطة القضائية.

و بالرجوع إلى قانون الإجراءات الجزائية المعدل بالأمر رقم 15 - 02 (14)، نجد أنه هناك العديد من الأصناف الذين منحهم المشرع الجزائري صفة ضابط الثرطة القضائية منهم

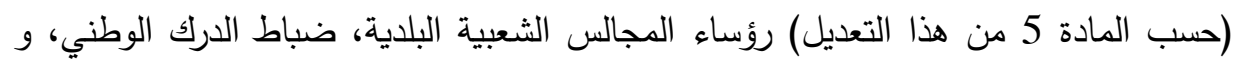

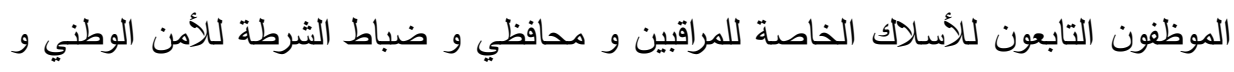
غيرهم...

كما أنه يعتبر من شروط توقيف الحدث الجانح للنظر ما أضافته المادة 1/49 و 2 من القانون رقم 15-12 السابق ذكره أنه يوقف الحدث الذي يشتبه في ارتكابه أو محاولة ارتكابه

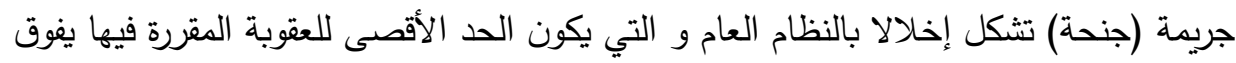

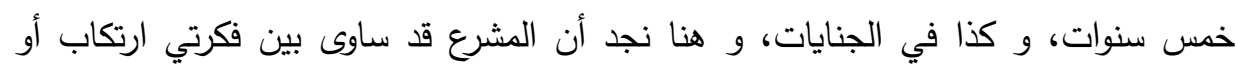

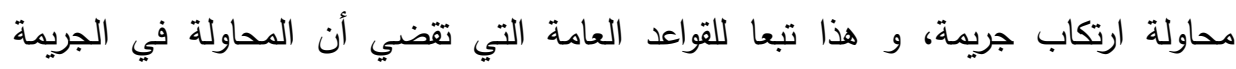

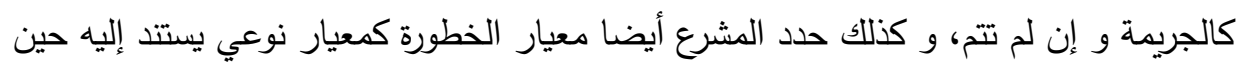
توقيف الطفل المشتبه فيه، و قد برزت حالة حصرية في هذا القانون و هي الجنحة التي تثكل

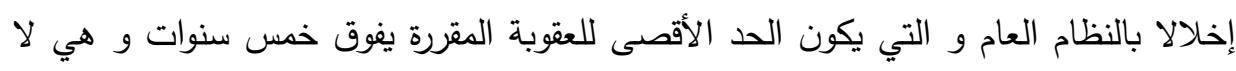
توجد كشرط في توقيف البالغين للنظر .

الفرع الثاني: آجال توقيف الحدث للنظر

لقد جاء في المادة 49 من القانون رقم 15-12 السابق ذكره أنه: "...لا يمكن أن تتجاوز مدة التوقيف للنظر أربعا و عشرين (24) ساعة..."، و التي تثابه تلك التي حددها قانون الإجراءات الجزائية الجزائري، و لكن نجد أن المشرع قد أضاف في نفرئ التس المادة أنه: "...يتم

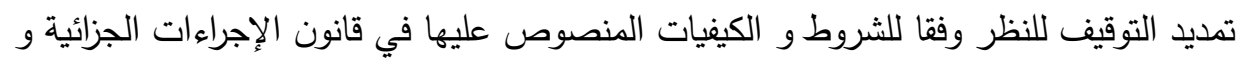

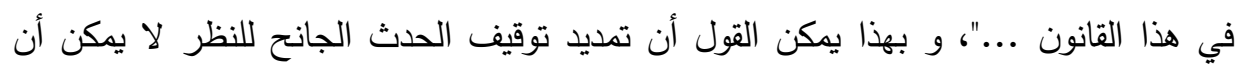

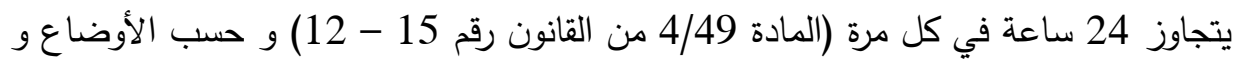
الشروط المنصوص عليها في قانون الإجراءات الجزائية و قانون حماية الطفل( المادة 
من القانون رقم15 - 12)، و لابد أن يقتاد الطفل المشتبه فيه أمام وكيل الجمهورية قبل انتهاء مدة 48 ساعة (المادة 2/51 من القانون رقم 15 - 12) و إن كان هناك دان داع للتمديد يمدد التوقيف للنظر حسب الأوضاع الواردة في المادة 51 و 65 من قانون الإجراءات الجزائية

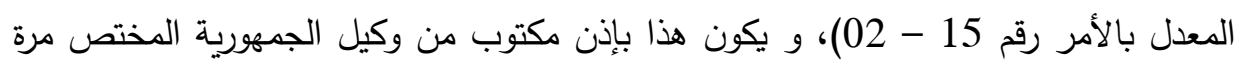

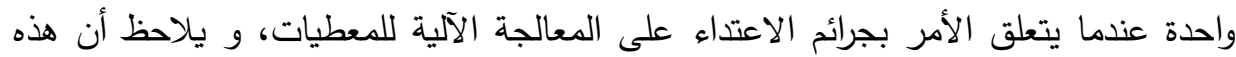

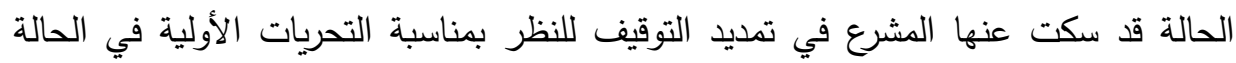

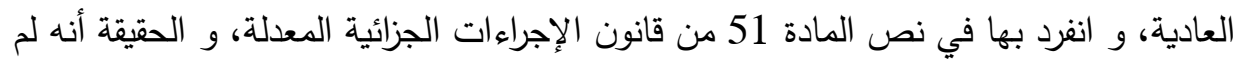

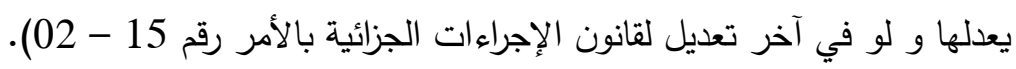

و يكون التمديد أيضا لمرتين إذا تعلق الأمر بالاعتداء على أمن الدولة، و ثلاث مرات إذا تعلق

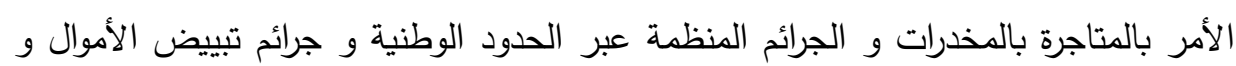

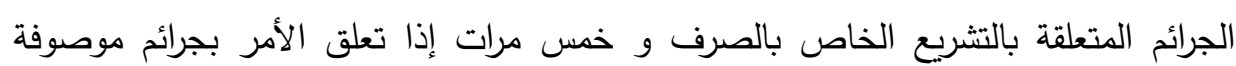
بأفعال إرهابية أو تخريبية و هي الحالات التي يمكن أن يمدد فيها توقيف الحدث المشتبه فئ فيه للنظر بأن

و هناك حالة تمديد بمناسبة تنفيذ أمر الإنابة القضائية من طرف ضابط الثرطة القضائية،

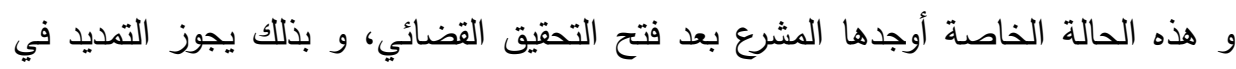
إطار تتفيذ أمر بالإنابة القضائية لمدة 24 ساعة أخرى من طرف قاضي التهاء التحقيق(الأحداث) المصدر للإنابة بقرار مسبب استثناء و هذا حسب المادة 141 من قانون الإجراءات الجزائية.

\section{المبحث الثاني: حقوق الحدث الموقوف للنظر و آليات احترامها}

إن المشرع الجزائري بإفراد تقنين خاص يوضح كيفية التعامل الإجرائي مع الطفل عموما و

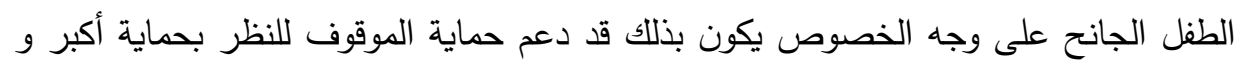
هذا في المشتبه فيه الحدث و قد نص القانون رقم 15 - 12 المتعلق بحماية الطفل على جملة من الحقوق صراحة و أكد عليها و هذا كله مدعم بالمبادئ العامة الموجودة في قانون الإجراءات الجزائية. 
المطلب الأول: حقوق الحدث الموقوف للنظر

لقد أقر المشرع للمشتبه فيه الحدث الموقوف للنظر حقوقا و قد دعمها بمبادئ و ضمانات دستورية فقد جاء في الدستور المعدل بالقانون رقم 16 - 01 (15) في المادة 38 منه أن:

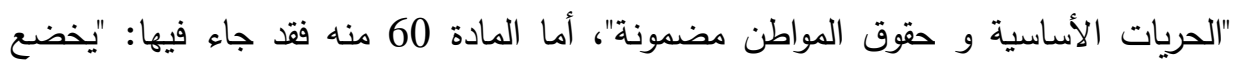

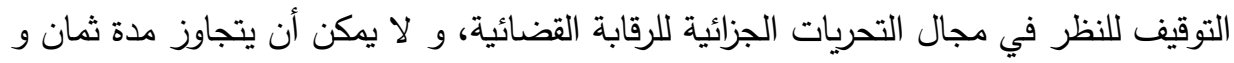
أربعين (48) ساعة.

يملك الثخص الذي يوقف للنظر حق الاتصال فورا بأسرته ... يحدد القانون كيفيات تطبيق

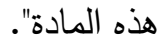

\section{الفرع الأول: حقوق الحدث الموقوف للنظر بصفته إنسانا}

تتنوع الحقوق التي تلازم الشخص بصفته إنسانا و هو ما يسقط أيضا على الحدث بغض النظر عن مركزه القانوني، فهو لله الحق في الغذاء و خصوصا في ظل إمكانية طول فترة التوقيف للنظر ، و هذا الحق و إن لم ينص عليه القانون رقم 15 - 12 المتعلق بحماية الطفل إلا أنه من الحقوق المحمية دستوريا، و قد ورد في نص المادة 1/25 من الإعلان العالمي لحقوق الإنسان المؤرخ في 1948/11/10 أنه: "لكل شخص الحق في مستوى من المعيشة

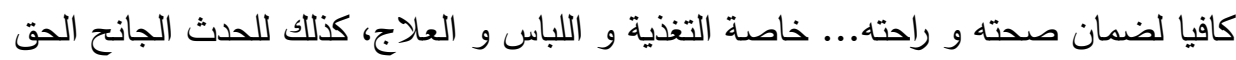

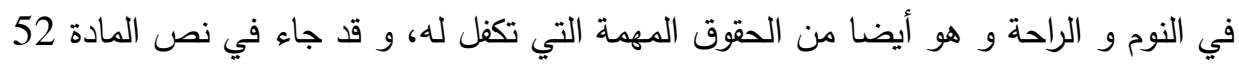

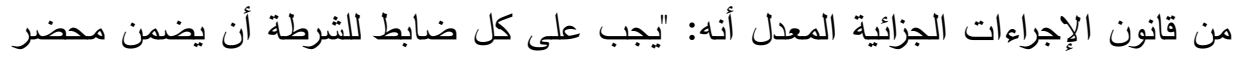

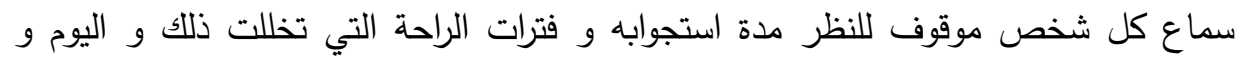
الساعة اللذين أطلق سراحه فيهما أو قدم إلى القاضي المختص...."، و بهذا ولتها لا يجوز إرهاق

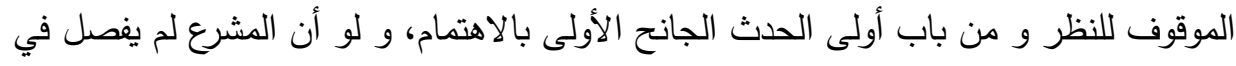
الحق في النوم إلا أنه باستقراء المواد 51 و 65 و 141 من قانون الإجراءات الجزائية فإنه

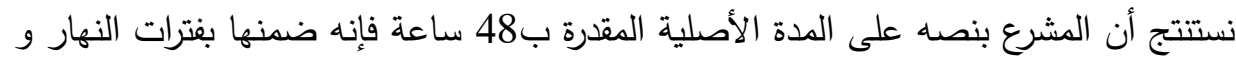

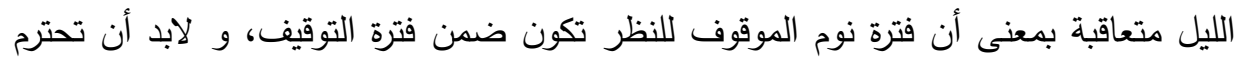

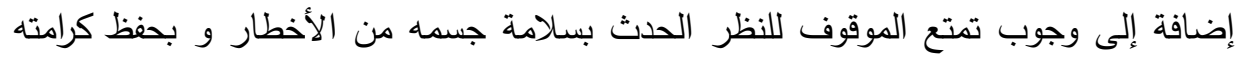


بصفته إنسانا، و هو أمر لم تهمله الشرائع الدولية أو الداخلية فقد جاء في الدستور المعدل

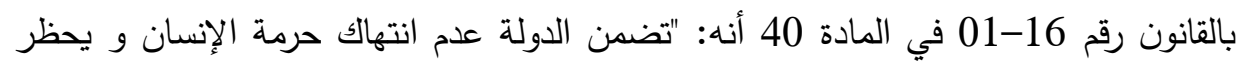

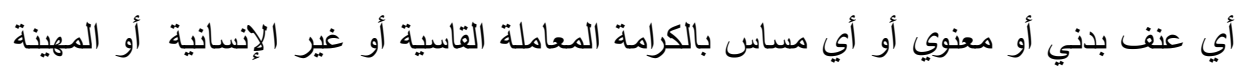

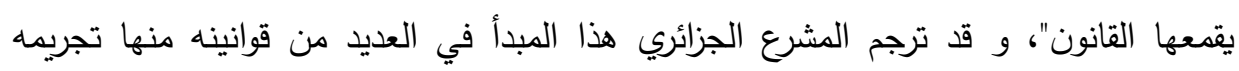
للتعذيب في المادة 263 مكرر من قانون العقوبات، و هو ما تأكد عليه الأصوات الدولية المناهضة للتعذيب و المعاملات المهينة أو الماسة بالكرامة (المادة 2 من اتفاقية حماية

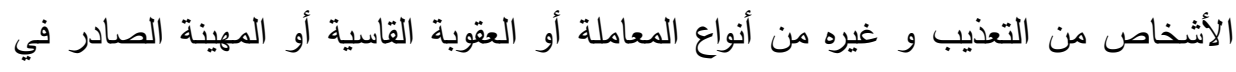

.(1974/12/10

\section{الفرع الثاني: حقوق الحدث الموقوف للنظر بصفته مشتبها فيه}

إن المشتبه فيه (16) هو من قامت حوله قرائن على أنه ارتكب جريمة، و الاشتباه في ذاته

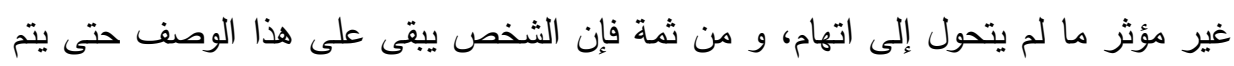

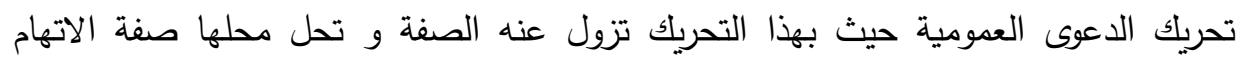

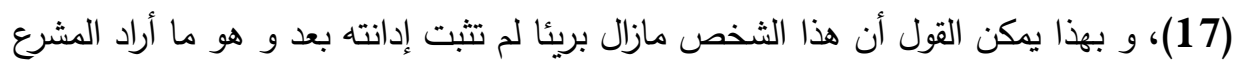

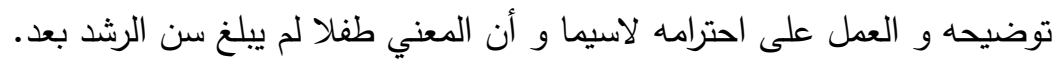

و قد أورد المشرع أنه يجب على ضابط الشرطة القضائية، بمجرد توقيف طفل للنظر إخطار ممثله الثرعي بكل الوسائل و أن يضع تحت تصرفه كل وسيلة تمكنه من الاتصال بعائلته

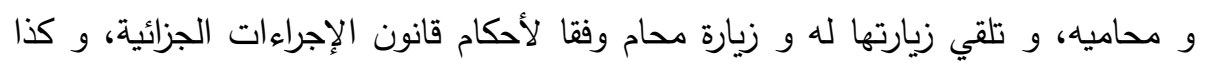
إعلام الطفل بحقه في طلب فحص طبي أثناء التوقيف للنظر (المادة 50 من القانون رقم 15 - 12)، كما يجب على الضابط إخبار الطفل الموقوف بالحقوق المذكورة في المادتين 50 و 54 من هذا القانون و يشار إلى ذللك في محضر سماعه.

كما يجب إجراء فحص طبي للطفل الموقوف من قبل طبيب يمارس نشاطه في دائرة

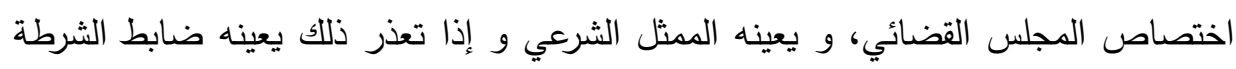
القضائية، و يمكن وكيل الجمهورية سواء من تلقاء نفسه أو بناء على طلب من الطفل أو ممثله 
الشرعي أو محاميه أن يعين طبيبا لفحص الطفل في أية لحظة أثناء التوقيف و يجب أن ترفق شهادات الفحص الطبي بملف الإجراءات تحت طائلة البطلان (المادة 51 من نفس القانون). كما يجب على الضابط أن يدون في محضر سماع كل طفل موقوف مدة سماعه و فترات

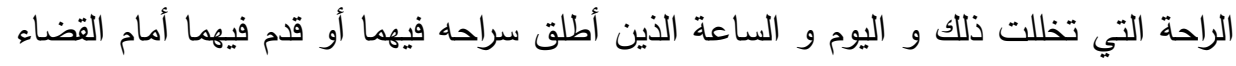

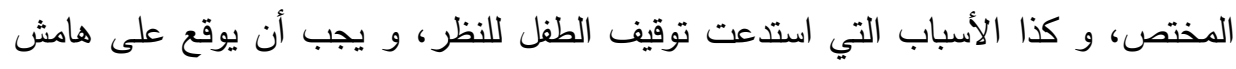

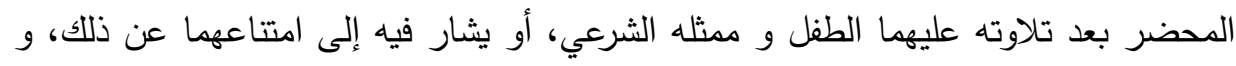
يجب أن تقيد هذه البيانات في سجل خاص ترقم و تختم صفحاته و يوقع عليه من طرف وكيل الجمهورية، كما يجب أن يمسك على مستوى كل مركز من مراكز الشرطة القضائية التي يحتمل أن تستقبل طفلا موقوفا للنظر .

و يجب أن يتم التوقيف للنظر في أماكن لائقة تراعي احترام كرامة الإنسان و خصوصيات

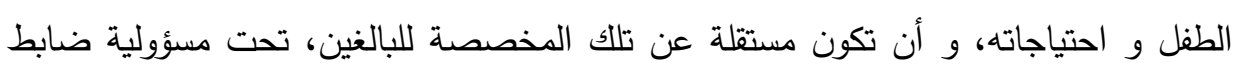
الثرطة القضائية(المادة 52 من نفس القانون). كما يجب أن تقيد البيانات و التأشيرات المنصوص عليها في المادة 52 من هذا القانون في

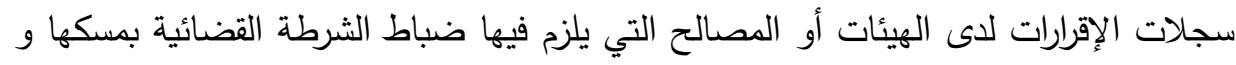

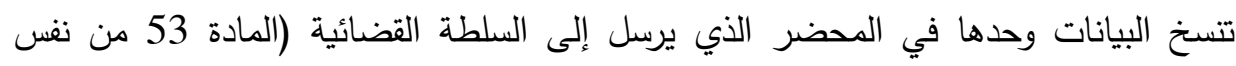

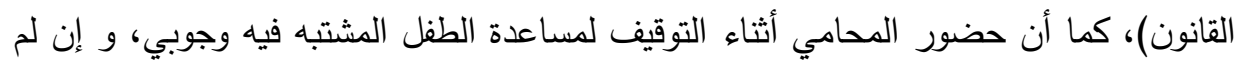
يعين للطفل محام يعلم الضابط فورا وكيل الجمهورية المختص لاتخاذ الإجراءات المناسبة التهاء

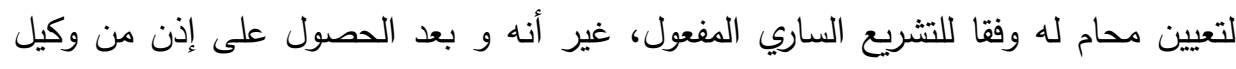

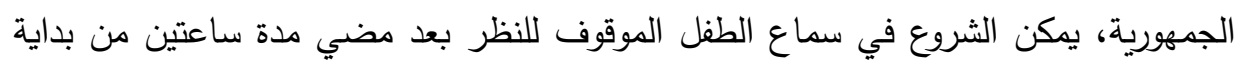
التوقيف للنظر حتى و إن لم يحضر محاميه و حتى في حالة وصوله متأخرا تستمر إجراءات السماع في حضوره.

و إذا كان سن المشتبه فيه ما بين سن 16 و 18 سنة و كانت الأفعال المنسوبة إليه ذات صلة بجرائم الإرهاب و التخريب أو المتاجرة بالمخدرات أو بجرائم مرتكبة في إطار جماعة وله إرهابية منظمة، و كان من الضروري سماعه فورا لجمع الأدلة أو الحفاظ عليها من أو للوقاية 
من وقوع اعتداء وشيك على الأشخاص يمكن سماع الطفل وفقا لأحكام المادة 55 من هذا القانون دون حضور محام و بعد الحصول على إذن من وكيل الجمهورية (المادة 54 من نفس

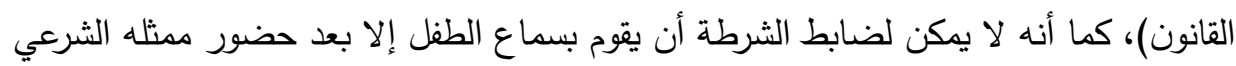
إذا كان معروفا (المادة 55 من نفس القانون).

المطلب الثاني: آليات احترام حقوق الحدث الموقوف للنظر

تعد الرقابة على إجراءات التوقيف للنظر من أهم الأمور التي يجب على القانون كفالتها

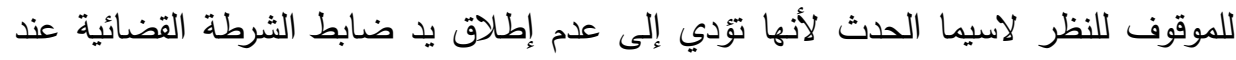

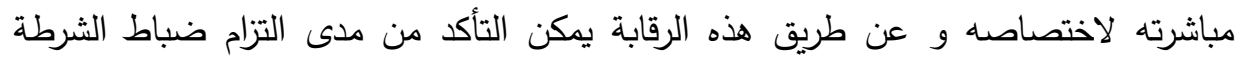
القضائية بضوابط التوقيف للنظر السابق بيانها دون أن يكون هناك أي تجاوز أو انحراف منها لهابها

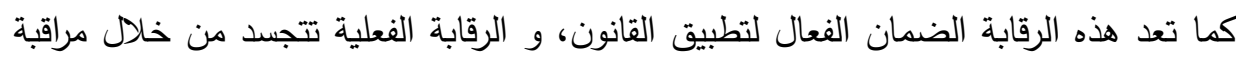

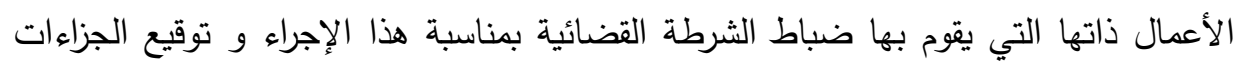

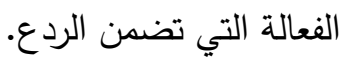

\section{الفرع الأول: أنواع الرقابة المسلطة على توقيف الحدث للنظر}

لا تتحقق الرقابة الفعلية إلا إذا تسلطت على الوسائل المادية الملموسة التي أطرها القانون،

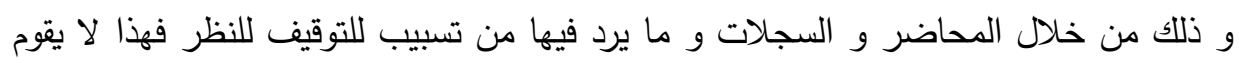
بتوقيعه ضباط الثرطة القضائية عبثا و إنما هم ملزمون بمسك دفاتر خاصة و وقد في أشار إليها

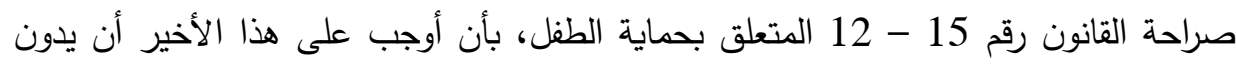

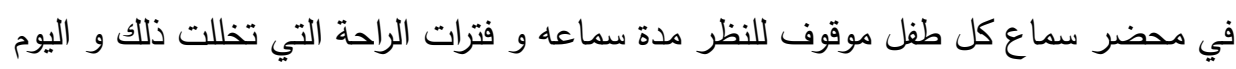

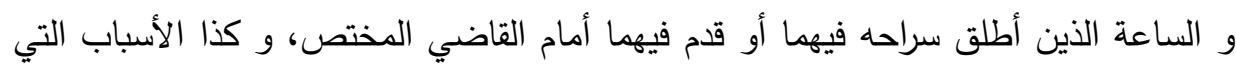

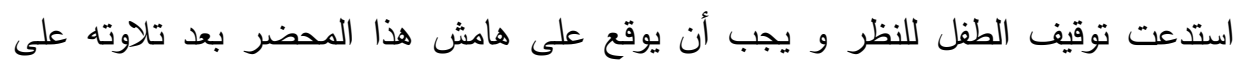

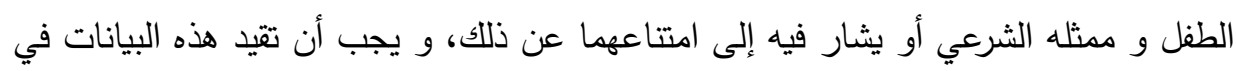

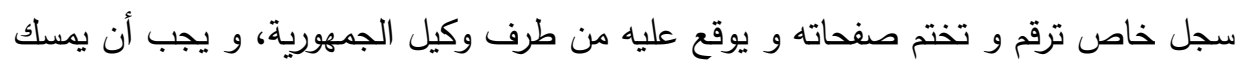
على مستوى كل مركز للشرطة القضائية الذي يحتمل أن يستقبل طفلا موقوفا للنظر (المادة 
52 من القانون السابق)، و هذا الأمر قد جاء تدعيما لما ورد في قانون الإجراءات الجزائية الذي لم يغفل هذه النقطة.

و تظهر أهمية ذكر أسباب التوقيف للنظر في نواح عديدة منها معرفة نوع الجريمة المشتبه

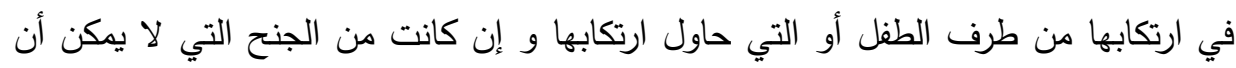
يوقف فيها للنظر و كذا معرفة سبب التمديد.

و رغم أهمية تسبيب إجراء التوقيف للنظر عموما و توقيف الحدث على وجه الخصوص

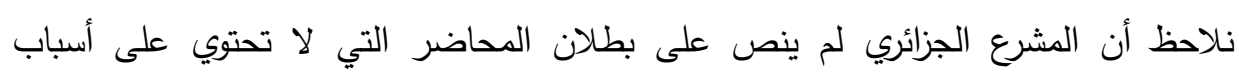

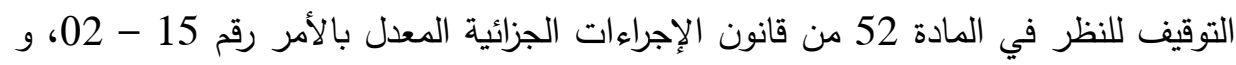

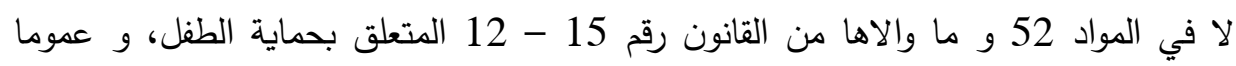
تعتبر المحاضر من المحررات التي يعتمد عليها كوسيلة من وسائل الإثبات الجنائي شريطة أن أن النايه

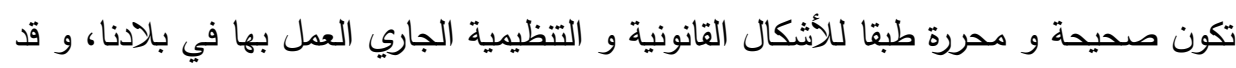
ورد في المادة 214 من قانون الإجراءات الجزائية: "لا يكون للمحضر أو التقرير قوة الإثبات

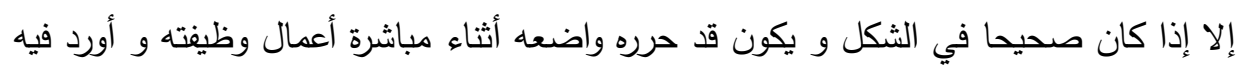
عن موضوع داخل في نطاق اختصاصه قد رآه أو سمعه أو عاينه بنفسه". و يخضع ضابط الثرطة القضائية عند ممارسة مهامه في التحريات إلى نوعين من التبعية، تبعية إدارية لرؤسائه الإداريين و تبعية وظيفية للنيابة العامة تحت مراقبة غرفة الاتهام

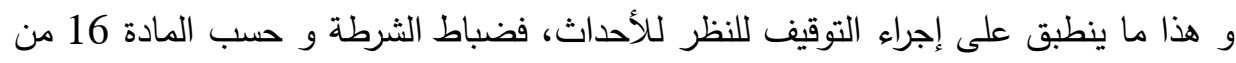

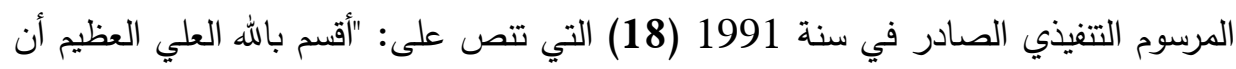

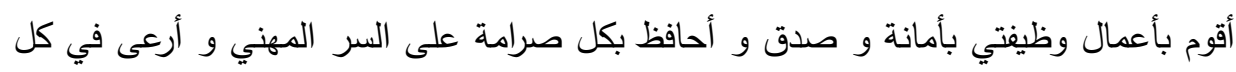

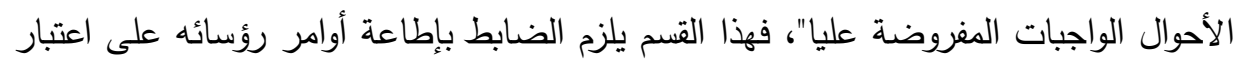
أنه واجب و يخضع لرقابته على أعماله لأن حسن انضباط الضابط من مسؤوليتهه، و تتم

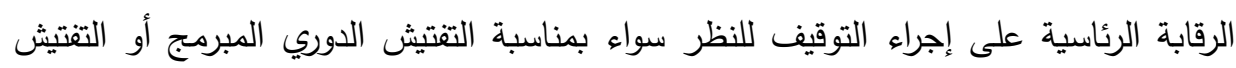
الفجائي الذي يشمل المسك الجيد لسجل التوقيف للنظر ، و مراقبة الاعتناء به شكلا و مضموناء و مراقبة نوعية المحاضر بغرض تصحيحها و تنبيه ضابط الثرطة القضائية للأخطاء 
و النقائص التي يمكن أن تتضمنها و لاسيما في البيانات الخاصة بتوقيف الحدث للنظر ، كما

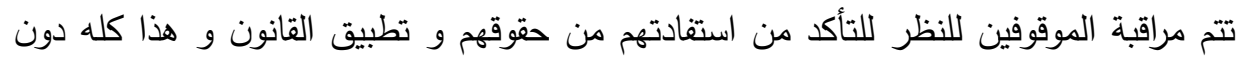
الخروج عن المبادئ العامة التي أقرها قانون العقوبات.

أما الرقابة القضائية الموقعة على الموقوف للنظر الحدث فتتدرج ضمن نطاق الرقابة على

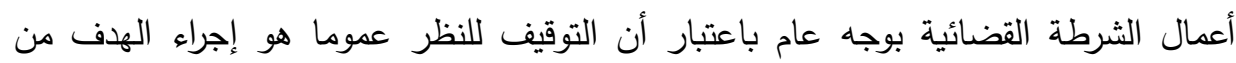
الرقابة عليه هو حماية الحقوق و حرية الموقوف للنظر الذي يعتبر مشتبها فيه، و تحرص الرقابة القضائية على أن تكون أعمال الثرطة القضائية شرعية و تتفذ في إطار القانون فقد

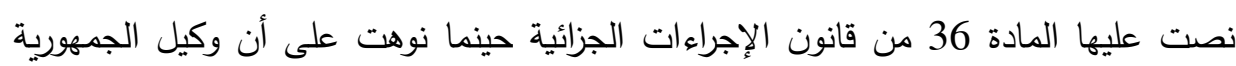
يدير نشاط الضبطية القضائية و يراقب تدابير التوقيف للنظر ، أما على صعيد القانون رقم 15

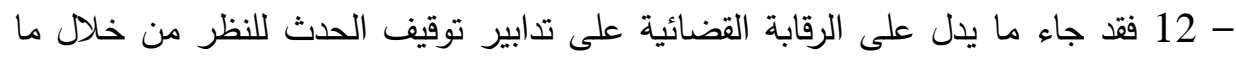

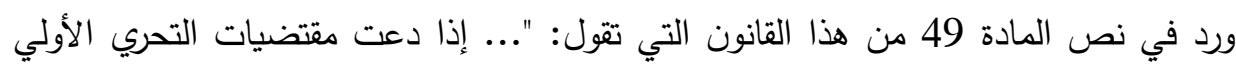
ضابط الشرطة القضائية أن يوقف للنظر الطفل... عليه أن يطلع فورا وكيل الجمهورية و يقدم التهان

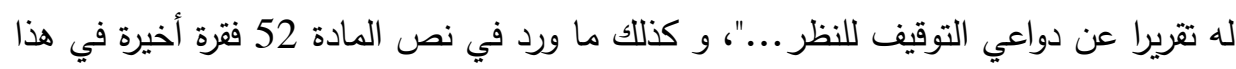
القانون أنه: "... يجب على وكيل الجمهورية و قاضي الأحداث المختصين إقليميا زيارة هذه الأماكن دوريا و على الأقل مرة واحدة كل شهر".

كما تظهر رقابة النائب العام على أعمال ضباط الشرطة القضائية حين توقيع هذا الإجراء

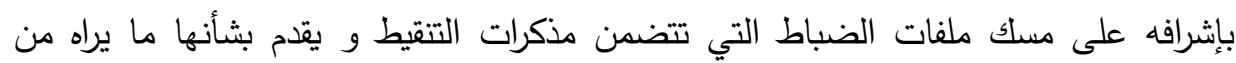
ملاحظات كما يتولى النظر في الاحتياجات التي يمكن أن يقدمها له ضباط الثرطة القضائية

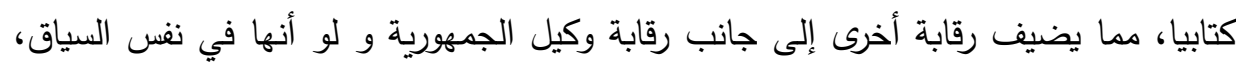

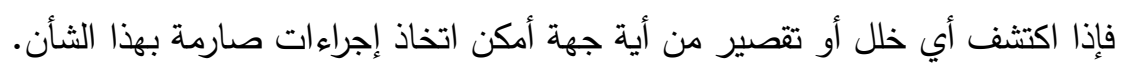

أما رقابة غرفة الاتهام على أعمال ضباط الشرطة القضائية و التي من بينها توقيف الحدث

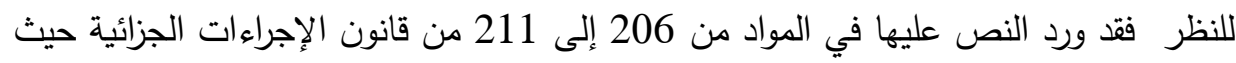

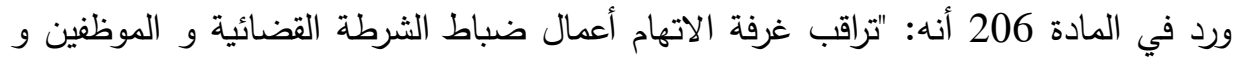
الأعوان المنوطة بهم بعض مهام الضبط القضائي التي يمارسونها حسب الشروط المحددة في 
المواد 21 و التي يليها من هذا القانون"، و هنا تكون الرقابة غير مباشرة و ذلك بعد وجود خلل من شأنه إيصال الدعوى إليها فتبث في المسألة.

الفرع الثاني: جزاء الإخلال بحقوق الحدث الموقوف للنظر

إن ملابسات توقيع التوقيف للنظر عموما يمكنها أن تنطوي على بعض الممارسات من

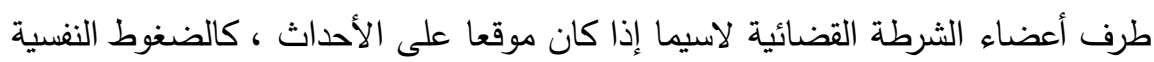

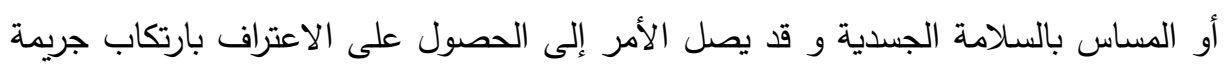

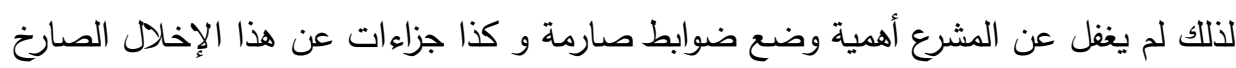
من أجل الموازنة بين البحث عن الحقيقة و ضمان الحقوق في نفس الوقت.

و تتنوع أوجه التعدي على الحدث الموقوف فقد تكون بالإكراه المادي الذي يؤدي إلى

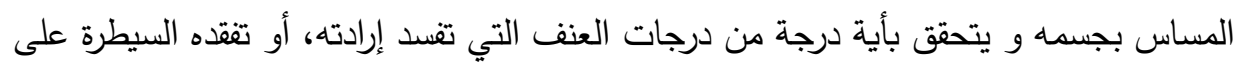

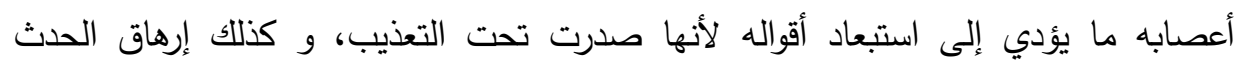
الموقوف من خلال إطالة فترات سماع أقواله.

أما الإكراه المعنوي فيتجسد بالضغط على إرادة الموقوف الحدث لتوجيهها إلى سلوك معين و

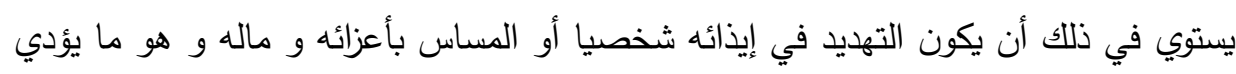
إلى قوله لما لا يريد.

كما قد يلجأ ضابط الثرطة القضائية إلى التعسف في استعمال سلطات الضبط، فيسيء استعمال هذا الإجراء كأن يصر على سماع الحدث الموقوف على أنه مشتبها فيه رغم أنه

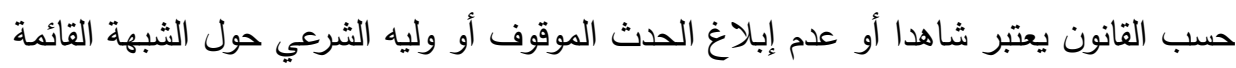

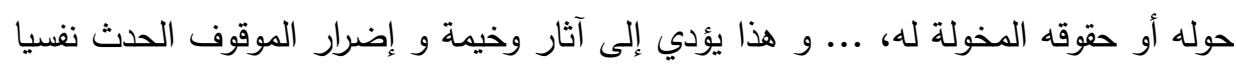

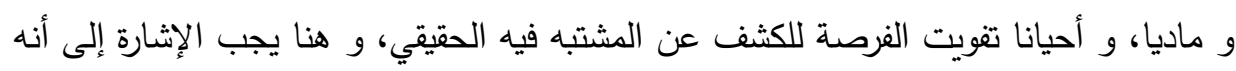

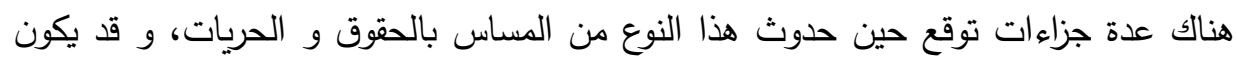
جزاء ماديا أو معنويا. 
أما الجزاء الشخصي فهو جزاء غير إجرائي ينال من شخص القائم به بما يطبق عليه من جزاءات جنائية أو مدنية أو تأديبية حسب الأحوال و الثروط المتوفرة، و أما الجزاء الإجرائي لئي لئي فيرد على الإجراء ذاته (19)، و إن كان الجزاء الموضوعي يبقى محل غموض عند البه المشرع إلا

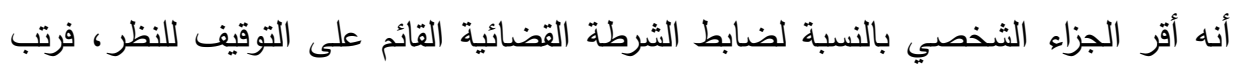

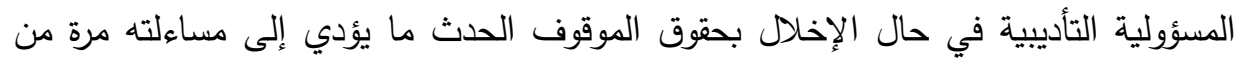
رؤسائه المباشرين و مرة بواسطة السلطة القضائية، لأنه ليس هناك من الناحية القانونية ما ليأه يمنع من تسليط عقوبتين تأديبيتين عليه (20).

فقد تكون العقوبة التأديبية إنذار شفوي أو كتابي أو توبيخ أو توقيف عن العمل من يوم إلى إلى

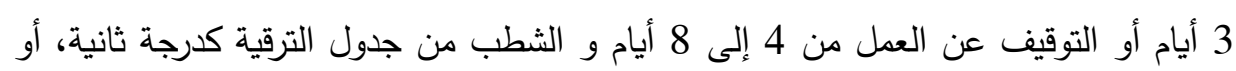

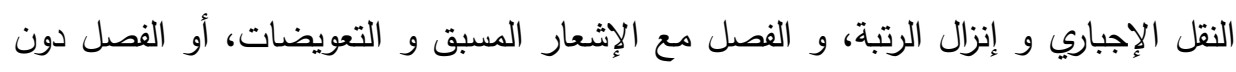
الإشعار المسبق و لا تعويضات كدرجة ثالثة، أو يكون التوقيف الفوري في حال الإخلال

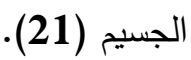

أما العقوبة التأديبية الموقعة من طرف السلطة القضائية فنجد أن المشرع لم ينص على

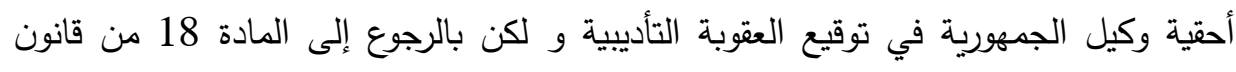

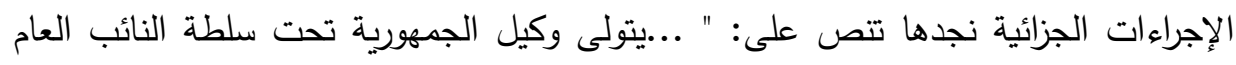
تنقيط ضباط الشرطة القضائية العاملين بدائرة اختصاص المحكمة، يؤخذ التنقيط في الحسبان

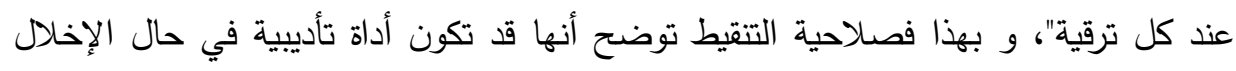
بمنح تتقيط أدنى يؤثر على الترقية.

كما أقر المشرع حين قيام المسؤولية التأديبية لضباط الشرطة القضائية لغرفة الاتهام توقيع

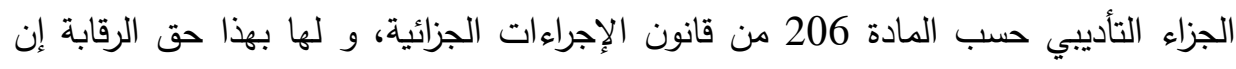
رأت ضرورة لذلك و لو كان قد تعرض للجزاء التأديبي من طرف رؤساءه و هذا حسب الجراه المادة

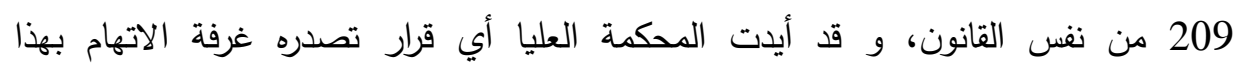

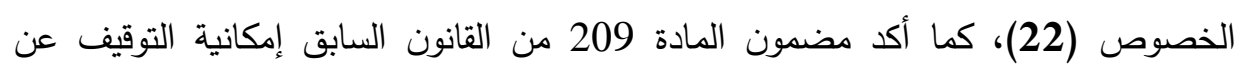

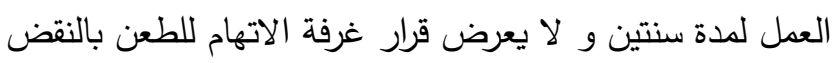


و توقيع الجزاءات التأديبية يكون بعد رفع الأمر إلى هذه الأخيرة من طرف النائب العام أو من طرف رئيسها حسب المادة 1/207 من قانون الإجراءات الجزائية.

أما المسؤولية الجزائية فهي أشد أنواع المسؤولية الشخصية أثرا نتيجة الجزاءات التي تقرها،

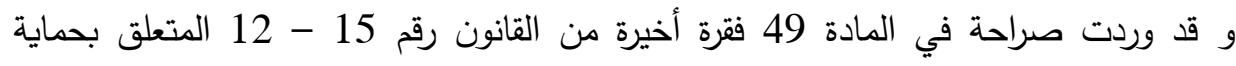

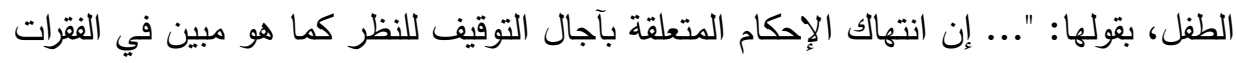
السابقة يعرض ضابط الشرطة القضائية للعقوبات المقررة للحبس التعسفي"، و هو ما بؤئيده

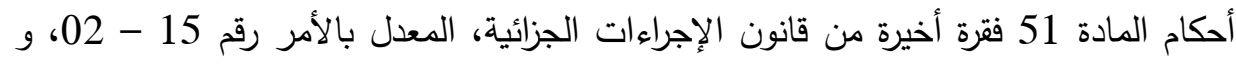
هو ما يؤيده أيضا بالتجريم و فرض عقوبة الحبس من شهر إلى ثلاثة أشهر و غرامة من 500

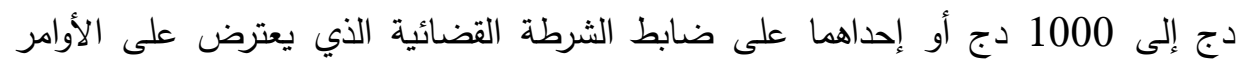

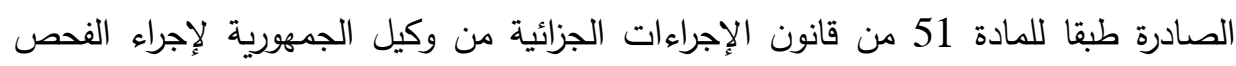
الطبي لشخص موقوف للنظر و منه الحدث، و هو ما يؤيده أيضا نص المادة 109 و 110 مكرر من قانون العقوبات. كما أقر المشرع المسؤولية المدنية لضابط الثرطة القضائية المعني بتعويض الضرر الذي أصاب الموقوف الحدث للنظر و بتوافر شروط الخطأ و الضرر و العلاقة السببية بينهما،

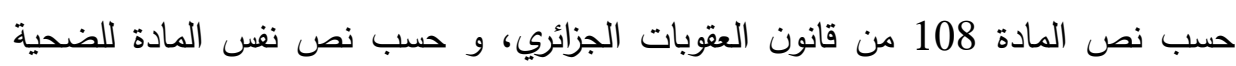
الحصول على تعويضها من الدولة ثم رجوع هذه الأخيرة على الفاعل بعد ذلك.

أما بطلان إجراء توقيف الحدث للنظر فلم يشر إليه المشرع الجزائري و كان الأولى مراعاة

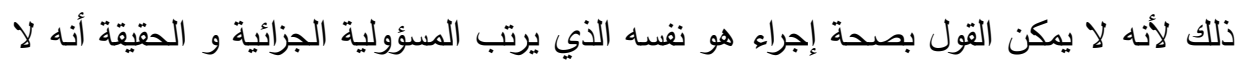

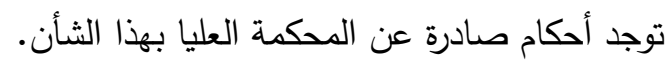

الخاتمـة

إن حساسية المرحلة العمرية للطفل و حساسية هذا الإجراء استدعى من المشرع النظر

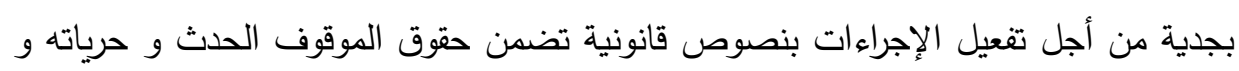

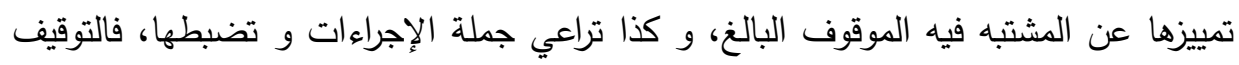


للنظر و إن كان غايته الحفاظ على الحقيقة من ضياع معالمها إلا أنه يعتبر على قدر كبير

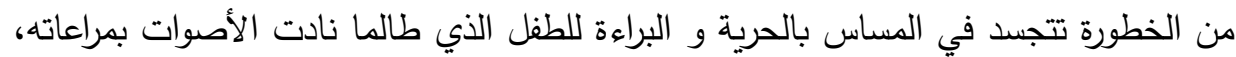

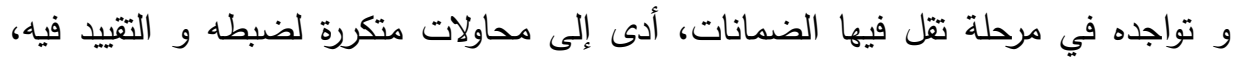
لاسيما في إطار تتامي الجريمة و انتشارها بين أطراف المجتمع.

و الحقيقة أن القانون رقم 15-12 المتعلق بحماية الطفل قد حقق به المشرع ققزة نوعية في مجال حماية حقوق الطفل، و لو أنه يعتبر استمرارية لأحكام قانون الإجراءات الجزائية و تأكيدا

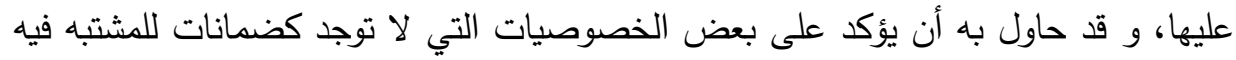

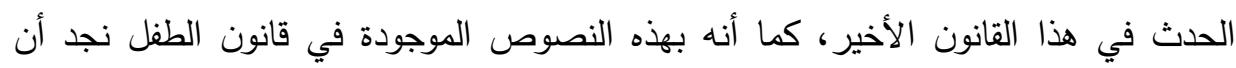

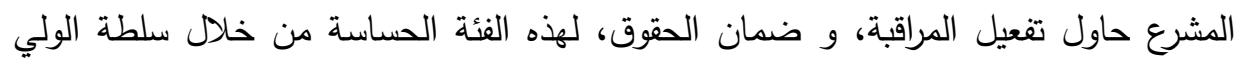

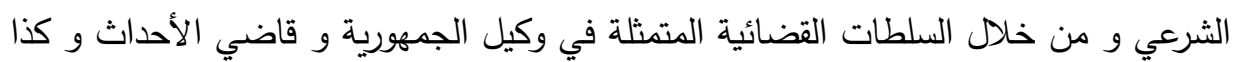
تواجد المحامي و الرقابة الطبية و غيرها من الضمانات المتوفرة من خلال هذا القانون.

كما أن المشرع قد لجأ إلى النص صراحة على تفعيل الجزاء الجنائي كأقصى درجات الحماية إضافة إلى الجزاءات الأخرى من أجل حماية الموقوف للنظر الحدث، و و هذا يعتبر

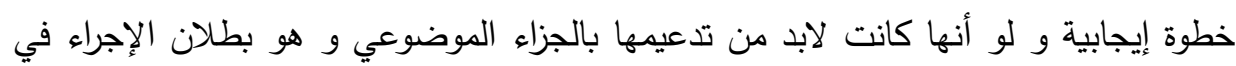

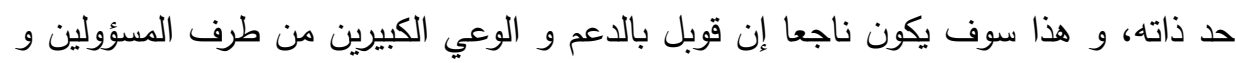
القائمين بهذا الإجراء على ضرورة الحفاظ على حقوقه و تطبيق الإجراءات بعينها دون استغلال أو تمييز أو إكراه أو تعسف.

\section{قائمة الهوامش}

1. أنظر القانون رقم 16- 01 المؤرخ في 2016/03/06 المتضمن التعديل الدستوري، الصادر في الجريدة الرسمية، عدد 14، الصادرة بتاريخ فيخ فئرئ

Stefani(Gaston), Levasseur(George),Bouloc(Gaston),procédure pénale $19^{\text {ème }}$. 2édition, paris, Dalloz 2004, p402.

3. المادة 2/28 من القانون رقم 01 - 22 المتعلق بالمسطرة الجنائية للممكة المغربية، المعدل بتاريخ 2015/06/01، صن 28 من من 28 
4. الفصل 13 مكرر من مجلة الإجراءات الجزائية التونسية، الطبعة 2، تونس، دار إسهامات في أدبيات المؤسسة، 2009، صن صن

5. محدة (محمد): ضمانات المشتبه فيه أثناء التحريات الأولية، الجزء 2، الطبعة 1، الجزائر ، الديوان الوطني للأشغال التربوية، 2004، ص ص .164

6. أوهايبية (عبد الله): ضمانات الحرية الثخصية أثناء البحث التمهيدي، طبعة 1، الجزائر،

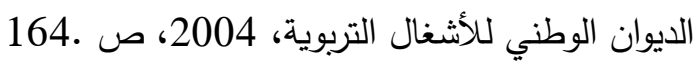
7. القانون رقم 15-12 المؤرخ في 2015/07/15، الدتعلق بحماية الطفل، الصادر في الجريدة الرسمية عدد 29، بتاريخ البرن في

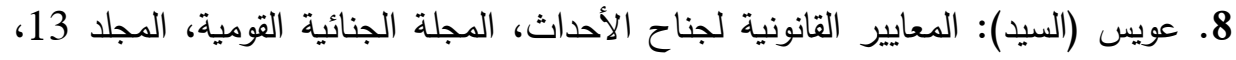
العدد 1 الجمهورية العربية المتحدة، المركز القومي للبحوث الاجتماعية و الجنائية، 1970،

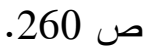

9. مخيمر (عبد العزيز): حماية الطفولة في القانون الدولي و الثريعة الإسلامية، (دون طبعة)، القاهرة دار النهضة العربية، 1990، ص 23 و ما بعدها.

10. إبراهيم دنصور (إسحاق): المبادئ الأساسية في قانون الإجراءات الجزائية الجزائري،

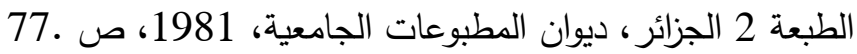

$$
\text { 11. محدة (محمد): مرجع سابق، ص } 173 .
$$

Brhincky Corinne (Renault), procédure pénale, $7^{\text {ème }}$, paris, Gualine éditeur .12 2006, p 135.

13. هي المادة المعدلة بالقانون رقم 01-08 المؤرخ في 2001/06/26، و الصادر في

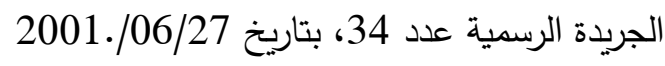

14. الأمر رقم 15-02 المؤرخ في 2015/07/23، المعدل لقانون الإجراءات الجزائية،

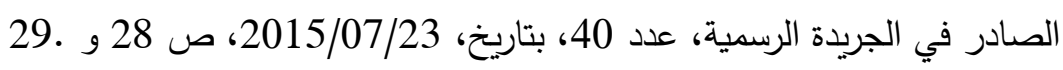


15. القانون رقم 16-01 المؤرخ في 2016/03/16، المتضمن التعديل الدستوري، السابق ذكره، ص 10 و 13.

16. و قد عرف الفقه الفرنسي المشتبه فيه بأنه:" الشخص الذي بدأت ضده مرحلة التحريات الأولية لقيام قرائن تدل على ارتكاب الجريمة أو مشاركته فيها و لم تحرك بعد الدعوى الجنائية

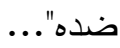

Merle(Roger), Vitu (André), Traité du Droit criminel, procédure pénale, $3^{\text {ème }}$ édition, paris, Cujas,1976, p 314.

17. محدة (محمد): مرجع سابق، ص .52

18. المرسوم التتفيذي، الصادر تحت رقم 91- 594، المؤرخ في 1991/12/25، الصادر في الجريدة الرسمية عدد 69، بتاريخ، 1991./12/28 19. أوهايبية (عبد الل): مرجع سابق، ص 328 و .329 20. المرسوم التنفيذي الصادر تحت رقم 91 - 594، السابق ذكره. 21. - 21. المادة 41 من نفس المرجع.

22. قرار صادر عن الغرفة الجنائية للمحكمة العليا، ملف رقم 105717، بتاريخ 1993/01/05 المجلة القضائية، عدد 1، بتاريخ 1994، صنس صرائ 247. 